\title{
Visiting Taro from a Botanical and Phytochemical Perspective
}

\author{
Meenakshi Sharma ${ }^{1}$, Arpitha Shankar ${ }^{2 *}$, Anand Kumar ${ }^{3}$, Anil Kumar Delta ${ }^{1}$ \\ ${ }^{1}$ Department of Chemistry, Ranchi University, Ranchi-834 001, Jharkhand, India \\ ${ }^{2}$ Department of Agriculture Biotechnology, Sardar Vallabhbhai Patel University of Agriculture \\ and Technology, Meerut-250 110, Uttar Pradesh, India \\ ${ }^{3}$ Department of Genetics and Plant Breeding, Chandra Shekhar Azad University of Agriculture \\ and Technology, Kanpur-208002, India \\ Correspondence: arpithashnkr94@gmail.com
}

\begin{abstract}
Taro is an important root vegetable and has several medicinal and therapeutic properties. The two major therapeutic ingredients are flavonoids and triterpenoids, which are of prime importance. Additionally, the plant has antibacterial, antiparasitic, antiallergic, and antiinflammatory properties. People often use it to treat a number of diseases by prescribing them as medications. Researchers from the pharmaceutical industry can thrive on C. esculenta by using whole-plant extracts. The identification of valuable terpenoids and therapeutics and their preparations are profusely dealt with in this article. Also, the new structural details of connective tissue are also studied as it helps researchers to investigate further uses of taro for humans, it is well known that xanthan can be obtained commercially as stabilizers, thickeners, binders, and more. It is essential to explore this plant for both medicinal and pharmaceutical properties.
\end{abstract}

Keywords: Botanical, Biochemical, Colocasia, Corm, Taro

\section{Introduction}

Indigenous medicinal plants have recently achieved more global importance. And these medicinal plants are very prolific. Rural people rely on medicinal plants, particularly in areas without health facilities. Research has shown that Colocasia esculenta, i.e., Taro, effectively treats various ailments ${ }^{1}$. Botanical, pharmacological, and chemical analysis of this plant is also an important part of this study. Several pharmacological properties have been studied, including analgesic, anti-inflammatory, anticancer, and lipid function. Furthermore, the plant is full of bioactive phyto components such as flavonoids, glycosides, and micronutrients. It is crucial to use it in the medicinal and pharmaceutical industries ${ }^{2}$.

Colocasia esculenta, the dense taro corm, is a tropical herb that was thought to be among the first plants to be cultivated, which is also called taro, kalo, dasheen or godere ${ }^{3}$. It is characterized by the leaves that form the end of the plant with wide tops of the ruffle. The flower is a spat, a section of the yellow corolla that tapers into a tube. The plant also has antibacterial and hypotensive effects. The decoction of the leaves stimulates menstruation and the rest of the body and is used to treat cysts. Additional plant parts are used to treat conjunctivitis and suppurative wounds. The corm is commonly found inedible when cooked ${ }^{4}$. This can be dried and processed into a powder before being ground into flour. Fresh and younger specimens can be roasted to effectively reduce the levels of calcium oxalate and/or oxalate salts, but not to entirely 
remove the crystals. Colocasia esculenta is a member of the Araceae family and is commonly known as taro. The plant's leaf juice includes stimulants, rheumatic agents, and styptic agents ${ }^{5}$. It may also be used to treat adenoids and hemorrhages, and it is frequently beneficial to buboes. Taro plants have been grown in the South Pacific for hundreds of years and are widely available in the tropics throughout India and Indonesia ${ }^{6}$.

Taro has long strings of heart-shaped or arrow-shaped leaves pointed toward the earth ${ }^{7}$. The cyaniding 3-hexoside and cyaniding 3-hexoside 3-anthocyaninidinidinidyl glycosides are released when the flower buds open. It is often applied topically to open wounds to prevent infection. Leaves resemble elephant ears, and they are 1-2 m each. In certain countries, the tuber is thought to be the only edible part of the crop. Leaves are also used as traditional medicines for traditional applications, but the effects seem to be greater in such situations ${ }^{8}$.

The edible corm and leaves are normally used for hepatic illnesses. The young leaves and twigs also contain vitamin $C$; however, the leaves and twigs have fewer vitamins. The substance is a component of calcium, phosphorus, thiamine, oxalic acid, flavones and flavonoids, including apigenin and luteolin ${ }^{9}$.In folk medicine, botanical ingredients (except chemicals) and their properties were widely used (relative to the aroma and taste of plant C. esculenta). C. esculenta is commonly used in the medical world for antidiarrhea, antipathy, antimicrobials, antiseptic, anti-diarrhoea, antimicrobial, antipanthetic, antipathic, antiparasite, antipyretic and antidiarrheal are also used. Current research shows potent pharmacological activities, including antibacterial and anti-inflammatory and anti-lipid, anti-inflammatory and antidhelmin ${ }^{1}$. It contains many chemical components used in a broad range due to its medicinal and chemical properties.

\section{Distribution and Botany}

Research has so far pointed to South Asia as the place of origin. Its cultivation started in South-East Asia and travelled through Japan and Indonesia, an archipelago of islands, before arriving in South China. Taro may have been cultivated in China and Egypt as early as long ago as 100 B.C. Then, about 2,000 years ago, an Arab merchant caravan took the wheel to West Africa, then the slave trade brought it to South America and finally to the Caribbean. Today, it is cultivated almost in every tropical and subtropical part and is a common worldwide species. The bulk of taro is located in West Africa. Caribbean and tropical Asian cuisines depend heavily on taro because it is plentiful ${ }^{10}$. Taro is an herbaceous plant that can reach a height of 1-2 meters and is composed of a central corm (just below the soil surface) from which leaves and roots expand upward and cormels, daughter corms, and runners (stolons) develop laterally. The fibrous root structure is primarily found in the top one meter of soil ${ }^{11}$. The corm of dasheen taro is cylindrical and big. It can reach a length of $30 \mathrm{~cm}$ and a diameter of $15 \mathrm{~cm}$ which is the plant's primary edible component. The corm is thin, globoid, and surrounded by many cormels (stem tubers) and daughter corms in eddoe varieties. Together, the cormels and daughter corms account for a sizable portion of the edible harvest in eddoetaro ${ }^{12}$. When daughter corms typically produce subsidiary shoots while the main plant is still developing, cormels typically stay dormant. They can produce new shoots only if left in the ground after the death of the main plant. Each cormel or daughter corm has a terminal bud at the tip and axillary buds in its body in the axils of the various scale leaves ${ }^{13}$. 
Corms, cormels, and daughter corms both have an internal form that is very identical. The outermost layer is composed of a dense brownish periderm ${ }^{2}$. The field parenchyma is densely packed with vascular bundles and laticifers. Idioblasts (cells containing raphides or packets of calcium oxalate crystals) are often present in the field tissue and any other taro plant component. The corm's density and woodiness rise with age. Occasionally, certain taro plants grow runners in the region. These constructs develop horizontally along the soil's surface for an extended period, rooting down at intervals to produce new erect plants ${ }^{14}$.

In both the eddoe and dasheen varieties of taro, the central corm serves as the plant's primary stem structure. Each corm's surface is labelled with rings indicating the connection points for scale leaves or senesced leaves. Axillary buds are found at the corm's nodal sites. The corm's peak reflects the plant's growth point and is usually situated on the ground floor. From the corm apex, the actively developing leaves emerge in a whorl ${ }^{11}$. These leaves are effectively the only recognizable component of the plant above ground. They establish the height of the plant in the area. Each leaf is composed of an upright petiole and a substantial lamina. The petiole measures $0.5-2 \mathrm{~m}$ in length and is flared out at the base where it connects to the corm, allowing it to clasp around the corm's apex efficiently. The petiole is thickest at the base and becomes thinner when it approaches the lamina. Internally, the petiole is spongy and densely packed with air gaps, which probably facilitates gas exchange while the plant is raised in swampy or submerged environments. Petiole binding to the lamina is pleated in most taro species, where it is attached somewhere in the centre of the lamina, rather than at the tip ${ }^{15}$. This peltate leaf attachment separates taro from tannia, which has a hastate leaf attachment, with the petiole connected at the lamina's tip.

A notable exception to this law is the "piko" category of taro found in Hawaii; they have hastate leaves, which is unusual for taro. Taro's lamina is $20-50 \mathrm{~cm}$ long, oblong-ovate in shape, with rounded basal lobes. It is complete (without serrations), glabrous, and dense. Insects potentially pollinate taro; the natural flowering rarely occurs in taro, it can be artificially induced by applying gibberellic acid,which aids in flowering. Each plant can produce several inflorescences; a small peduncle, spadix, and a spathe comprise the inflorescence. In botanical terms, the spadix is a spike with a fleshy central axis on which the tiny sessile flowers are connected. The spadix is $6-14 \mathrm{~cm}$ in length, with female flowers at the root, male flowers at the top, and sterile flowers in the area squeezed by the spathe's neck in between. The spadix's drastic edge, which is devoid of flowers, is referred to as the sterile appendage. The sterile appendage serves as a distinguishing taxonomic feature of dasheen and eddoe varieties of taro ${ }^{16}$. The spathe is a broad yellowish bract measuring approximately $20 \mathrm{~cm}$ in length that sheathes the spadix. The lower portion of the spathe is closely wrapped around the spadix, totally concealing the feminine flowers.Under natural circumstances, fruit set and seed generation occurs infrequently. When fruits are made, they are located at the lower portion of the spadix ${ }^{17}$. Each fruit is a berry that measures between 3 and 5 millimetres in diameter and contains various seeds. Each seed has a tough testa and comprises both endosperm and embryo.

\section{Growth Cycle}

Taro is an herbaceous plant that survives year after year with the use of corms and cormels. Rapid root development occurs immediately after planting followed by shoot growth. At approximately six months after planting, shoot growth and total shoot dry weight begin to 
decline rapidly. The number of active plants decreases, the mean petiole duration decreases, the average leaf area per plant decreases, and the mean plant height decreases in the region.

Throughout the season, there is a fast turnover of leaves; fresh ones unfurl from the centre of the whorl of leaves while the older ones below die. Leaf obsolescence at this scale is physiologically inefficient ${ }^{18}$.Corm formation begins approximately three months after planting, and cormel formation occurs shortly afterwards in cultivars that contain significant cormels. By the sixth month, when shoot development has slowed, the corms and cormels have established themselves as the primary sink and are rapidly growing. The shoot's deterioration accelerates when the adverse (dry) season approaches until it fully dries out. The corm and cormels allow the plant to thrive in adverse conditions. If they are not picked, they sprout and produce new plants until the next favorable season arrives. Flowering begins in the early part of the season in the few cases that it usually occurs. The slender, cylindrical nature of the stamen normally intersects between the females and stamens. Sulcate albuminous abundant bloated rhizomes appear above the ground from a tuberous $\operatorname{root}^{19}$.

\section{Antinutritional factors}

Food crops regularly eaten have many beneficial nutrients. Still, there are traces of antinutritional components such as cyanoglucosides, oxalates, phytic acid, phenolics, protease inhibitors, heavy metals ${ }^{20}$ and tend to contain certain substances that interfere with nutrient uptake in the human body ${ }^{21}$. In the corms, 275-375 $\mathrm{mg}$ of oxalate is contained in fresh leaves and corms. Thus, the oxalic acid content was measured to be around $43 \mathrm{mg} / 100 \mathrm{~g}$ of fresh taro (or $43 \mathrm{mg}$ of total oxalate). As pasteurization progressed, water absorption markedly increased due to pasteurization ${ }^{22}$. Tamarind preparation (also known as tamarind roasting) is effective for softening while not damaging the cuticle. In hydrolysis, water and acid combined to help to reduce the amount of oxalic acids. The soluble oxalate content of the raw leaves was $236.10 \mathrm{mg}$ oxalate/100 g wet matter (W.M.). Soaking the raw leaves in water for 30 min marginally reduces the soluble oxalate content by leaching into the tap water,soaking for $18 \mathrm{~h}$ results in a $26 \%$ reduction in the soluble oxalate content of the raw leaves. Same way phytates can be removed, both the oxalates and phytates are to be removed because they decrease iron, zinc, magnesium, and calcium ${ }^{23}$.By following these few methods like washing, par-cooking, blanching, parroasting, and microwaving sweet potatoes, each of which accomplished $99 \%$ of the job. Complementary mal-absorption, including oxalates, can occur up to $2.05 \%$ of dietary malabsorption $^{24}$. Several other anti nutrientsubstances like tannins, Cyanide and trypsin inhibitors can be deactivated from taro by soaking, sprouting, or boiling the food before eating. Microwavements are good at eliminating anti-nutrients, and the consistency of the meal increases. The overall nutritional value of Colocasia will be significantly improved if it is boiled for $30-$ or even up to 45 minutes $^{25}$.

\section{Antimicrobial activity of colocasia}

Various preliminary steps include examining potential bioactive agents (detection and characterisation) and necessary for assessing medicinal plants' therapeutic properties. Researchers are very curious about indigenous pharmacologic methods of the use of medicines from the pounded or peeled leaves and fruits extracts, even if they do not have proper dosing profile. However, these methods make them interested in finding pharmacological solvents so 
called bioactive compounds such as flavonoids, tannins, terpenes and kohaps or simple, methanol solvent terpenes such as vanillin are ready to be soluble due to the relative high polarity of vanillin (5.1). As this research shows that methanol has been recognized for advantages in medicinal plants beforehand, it has been widely used, it is reasonable to make this extensively available for higher antioxidant activity ${ }^{5}$ i.e., $81.77 \%$ in the $C$. gigantea study. This relevant research involves studying the in vivo effects, molecular imaging (in silico) computations with respect to antimicrobial activity from the proximate phytochemical metsol extract, which is active against biological mediators as well as in vitro and inorganic antimicrobial effects.

The rhythmic contractions of the muscles, which regulate the movement of the intestines, can break down if the gastrointestinal tract itself is out of balance which can lead to diarrhoea ${ }^{26}$. The primary inhibitors in diarrheal energy can be used to release prostatic prostaglandins, which then help in the section of the bowels and water and promote the loosening of stauros and diarrhea prostaglandin ${ }^{27,28}$. Methanol production in the body, and thereby reducing blood prostaglandins, several methods that are greatest by eliminating prostaglandins (over an extended period of time). Flavonoids and alkaloids are present in plant extracts and therefore reduce COX1 and LOX, inhibiting prostaglandin and autacoid development, which prevents the formation of prostaglandins and autacoids. The polyphenolic compounds called flavones also show antidiuretic activity, have a broad range of effects, including antioxidants, antiinflammatory agents and anti-gasthenics.

The composition of the extract is important in antimicrobial activity, the capacity of the extraction solvent is crucial, the responsibility, solubility and potential of the active compound for interaction with the test medium, and overall solubility, are the key factors and a significant role is played by the method of examination. In previous research, several of these compounds (geraniolates and derivatives), including alkaloids, flavonoids and glycosides and terepenoic acids, appear as antimicrobials ${ }^{9}$. From the study, giants were found to be very susceptible to bacterial types tested. Therefore, giant leaf methanol extract may be regarded as a source for future studies of antimicrobial components

Polyphenol extract containing extract group hydroxyl is also a by-product of free radicals having lipophilic properties and neutralising free oxidative radicals. In the fight against diseases that were found to employ several reactive molecular species, including age oxygen and free radicals, flavonoids have both single and triple peroxides and decomposing peroxides the flavi are believed to have better capability for single oxygen, free radical quenching and decomposing as well as for free radical treatment. C. Radical scavenging with IC50 of $67.68 \mu$ depends on concentration. For the total radical antioxidant capacity (TAC) of mega plants using DPPH as an analytical biomarker, we found an IC50 for DPPH $(67.68 \mathrm{~g} / \mathrm{c} / \mathrm{mL})$ and an overall phenolic extract of $(39.01 \mathrm{~g} / \mathrm{mL})^{29}$. Species, alkaloids, flavonoids and terpenoids are the main contributors to antidiarrheumatic and antioxidant properties of methanolic extracts from the giant. Hydrogen donation ability can be present at higher amounts to important tissues and can act as an important antioxidant for a common C-propertince ${ }^{30}$.

Researchers explored the biological interactions between a natural product and its binding sites for proteins through extensive biochemical experiments and molecular modelling in order to ascertain the activity of the product's nature. This describes multiple likely patterns that 
provide additional contexts for the binding sites within the pockets for protein-protein interactions ${ }^{31}$. Since these results are partly responsible for phytoconstituents antimicrobial and antioxidant properties, it is safe to conclude that phytoconds also have antidiarrheumatic or antioxidant properties. Every bioactive compound so far been used to assess the pharmacokinetics, pharmacodynamics and physical/structural properties by using ADME methodology as a test case study for prediction-software. The Lipinski rule, which states that all bioactive substances act orally, can also explain that. The liquid is considered to be highly permeable and bio-available with a low molecular weight, hydrophilic and lipophilic properties.

\section{Phytochemicals in the Different Plant Parts of Taro}

Taro is rich in polyphenolic compounds and enhances the well-being of people. Carotenoids have very high levels of anti-cancer agents that exist spontaneously and other possible benefits. 2 is transformed to vitamin A twice, while $\alpha$ carotene affects only once Starchy root taro foods include glucoside anthocyanidine Anthocyanins and the other properties that also improve the blood circulation and are believed to have strong antioxidemic, fragile and antiarterio-sclerotic properties the growth of human cancer cells is thought to be inhibited (Taro flour, made out of corms and dried from the heat, was found to have clear stuttering ${ }^{32}$. Abaxial and adaxial anthocyanin are also related to this.

The pHeterogenous peroxide, which has improved as a result of phthalate, was determined by the Colocasia solid phase chromatography process. The solution had been mixed at the same speed as $1 \mathrm{ml}$ a minute. The machine worked correctly with the usage of a conductivity monitor. Every oxalate was also tested independently in water in $1 \mathrm{~N} \mathrm{HCl}$ solution. Liquid cyanide in comparison to strontium contrast was almost as simple to count. Oxalate content of 19-87 mg per $100 \mathrm{~g}$ of new weight was present in nine cultivars. The insoluble content of oxalate in managed corms ranged from $29.35 \%$ to $73.97 \% 33$. Oxygen is a valuable tool for oxalates reduction. the existence of oxalates that give a sour taste or taste bad if cooked or prepared with salt ${ }^{34}$. It appears and behaves like a herb just when viewed closely, though it remains paired as it wilts. In naturally occurring patterns, leaves are much more or less flaccid with one direction: down or up ${ }^{35}$. One type has stem colors that may be shorter or extended and the other has stem colors which are red and black. In the majority of cases, the abundance of innumerable roots, it is expected that a lot of starch is obtained from the adventitious and shallow root system ${ }^{36}$. Elephants have leaf-wide leaves that grow to a maximum of $1.0 \mathrm{~m}$ in height and are known as "pliable and expansive." Tall, fast-growing leaves with dimensions of approximately 30 to $90 \mathrm{~cm}$ and 23 inches $^{37,38}$. Its maximum growth is 2 meters. up to five inflorescences and down to two or three rhizomes ${ }^{39}$. Taro roots are roughly $30 \mathrm{~cm}$ across and 15 $\mathrm{cm}$ in length.

It is good for fighting aging. Taro has been widely recommended for self-healing and weight loss. An important characteristic of this species is that the most abundant variety of bioactive plant extraction testing will assess large plant percentages of extracts to see if they can be applied as medical treatments to anti-inflammatory and anti-hypertensive properties ${ }^{40}$. Taro root extracts have been found to be a source of phytochemicals that can have minimal to substantial effects on the animal and human kingdoms. In order to make flavonoids and triterpenoids, approximately ninety percent of the plant's total mass is usually extracted from the roots and leaves. Colocasia is that it contains $\mathrm{CaCO} 3(\mathrm{PO} 4)$ and minerals like $\mathrm{CaP}$ and various 
vitamins, like vitamin $\mathrm{A}, \mathrm{D}$, and so on ${ }^{41}$. What analytical tests reveal about anthocyanins (specifically, anthocyanins such as anthocyanidin-3-3-glucans and cyanidin-argin3-arg) turns out to be blue pigment in the Colocasia extract. In recent testing, these anthocyanins were shown to be toxic to cancer cells, which may account for their recently observed effect of increasing tissue regeneration. In Colocasia, anthocyanins are said to have a liver-protecting role, which is why they're thought to be found in the stems. This is due to their presence in the stems potentially inhibiting lipid movement.

In rubescent and itch, the plant juices will be absorbed. Still, they will have no effect on aderumet's and related skin conditions, such as rheumatoid, itch disease, or any other issues involving bleeding. The corm juice has an effect of a laxative, a nauseant, pain reliever, and an emetic. a compound known to be beneficial in treating and preventing parasitic infection and disease has been found in a case to be anti-carcinogenic ${ }^{36}$. Scientists estimate that these species are more than half a billion years old as well as present-day Europe, and the Far East. Where we live, the tropics have been torn up by giant machines. That plant's juice is both a styptic and anesthetic ${ }^{42,43}$.

The polysaccharide acrylamide fiber content of healthy plants, such as tubers and roots, increases the availability of polysaccharides. Due to the high moisture in rice, which is half of its calories, it has around $33 \%$ of the overall caloric content of the food, greater nutrient yield per weight. The fraction of protein in a given weight in water ${ }^{25}$ (two percent of a given weight). As the taro yields twice as much sugar as potatoes per $100 \mathrm{~g}$ of the plant, it can supply $15 \mathrm{~g}$ of protein per $100 \mathrm{~g}$ of it (with a net carbohydrate ratio of 11 percent). Like yam and manioca, other plants were thought to have little effect on the yield ${ }^{44}$. Also, the taro has a very low protein and lipid content and supplies substantial minerals and vitamins. Zinc and vitamin B are contained in higher amounts in novel cultivars regarding its relative position of importance ${ }^{45-47}$.

\section{Conclusions}

Medicinal plants are multinational but still play an important role in preserving the local identity. Many plants are endowed with various medicines that can be used throughout the world. The usefulness of medicinal plants especially lies in underdeveloped rural and poverty-stricken populations, especially in areas without modern medical facilities. In the current study, the current clinical evidence indicates that C.E. is used for the management of certain common diseases. Anything that has been gathered in the research we've conducted so far regarding botanical, phytochemical, and pharmaceutical studies is mentioned here. Various pharmacological operations have been investigated, including analgesic, anti-inflammatory, anticancer, and anti-inflammatory. These include irritation; anti-snoring, antiarrhythmic, and nervine activity; and anesthetic; and hyperlipidemia and anxiety have also been investigated. Other factors are the chemicals in the plant that provide plant antioxidants, such as flavonoids, sterols, and other micronutrients. For such biochemical processes, they are known as "radical scavengers." Thus, the observed chemical action is known as antioxidant operation, a phytochemical since they are used in plants much of the actionable free radicals are present in fresh fruits and vegetables. Herbal and pharmaceutical additives are plant phytochemicals. antimicrobial, antifungal and antirheumatic functions. Plants use them in growth and production, much of the time. Most plants are said to benefit from these stress reducers, such as sun and drought. Phytochem has wide applications in nutrition. 


\section{References:}

1. Kirtikar KR, Basu BD. Indian Medicinal Plants. Dehradun: International Book Distributors. 4:2615; (2005).

2. Linus., Edible Aroids: Post-Harvest Operation, Massey University, Private Bag 11-222, Palmerston North, New Zealand Massey University, (2003).

3. Ashok, Chandrasehkarappa. Taro (C. esculenta ) :An Overview (2018).

4. Kaushik P, Andújar I, Vilanova S, Plazas M, Gramazio P, Herraiz FJ, et al. Breeding vegetables with increased content in bioactive phenolic acids. Molecules. (2015).

5. Kaushik P, Saini DK. Silicon as a vegetable crops modulator-A review. Plants. (2019).

6. Priyanka V, Kumar R, Dhaliwal I, Kaushik P. Germplasm Conservation: Instrumental in Agricultural Biodiversity-A Review. Sustainability. (2021).

7. Adane, Shimeli. Effect of processing method on the proximate composition, mineral content and antinutritional factors of taro (colocasia esculenta, 1.) Grown in Ethiopia, (2013).

8. Matthews PJ, Agoo EMG, Madulin DA, Tandang DN. Ethnobotany and ecology of wild Taro (Colocasia esculenta) in the Philippines: Implications for domestication and dispersal. SenriEthnol Stud. 78:307-340 (2012).

9. Kazmi SA, Yang Z, Hong N. Characterization by small RNA sequencing of Taro bacilliform C.H. virus (TaBCHV), a novel badnavirus. PLoS One 10, e0134147; (2015).

10. Rao, V.R.; Hunter, D., Eyzaguirre, P.B., Matthews, P.J. Ethnobotany and global diversity of taro. In The Global Diversity of Taro; (2010).

11. Akwee PE, Netondo G, Kataka JA. A critical review of the role of taro Colocasia esculenta L. (Schott) to food security: a comparative analysis of Kenya and Pacific Island taro germplasm. Scientia Agriculturae 9, 101-8, (2015).

12. Temesgen, M.; Retta, N. Nutritional potential, health and food security benefits of taro Colocasia esculenta (L.): A Review. Food Sci. Qual. Manag., 36, 23-30; (2015).

13. Hunter, D., Eyzaguirre, P.B., Matthews, P.J. Ethnobotany and global diversity of taro. In The Global Diversity of Taro:Ethnobotany and Conservation; (2010).

14. Laxminarayana, Regional Centre, Central Tuber Crops Research Institute, Dumuduma, (2020).

15. Lebot V. Tropical root and tuber crops: cassava, sweet potato, yams, aroids, CAB International, Oxfordshire, U.K., 279-360; (2009).

16. Madulin DA,Matthews PJ, Agoo EMG, Tandang DN. Ethnobotany and ecology of wild Taro (Colocasia esculenta) in the Philippines: Implications for domestication and dispersal. SenriEthnol Stud.; 78:307-340; (2012).

17. Quiwei H, Qingdian L. Research \& development of Shangdong taro for high-value products and exports"' In: D. Zhu, P. V. Eyzaguirre, M. Zhou, L. Sears and G. Liu (eds) Ethnobotany and genetic diversity of Asian taro: focus on China. Proceedings of the symposium on ethnobotanical and genetic study of taro in China: Approaches for the conservation and use of taro genetic resources. Laiyang Agricultural College, Laiyang, Shangdong, China, International Plant Genetic Resources Institute, Rome, (2000).

18. Nunes, R.S.C.; Del Aguila, E.; Paschoalin, V.; da Silva, J. DNA barcoding assessment of the genetic diversity of varieties of taro, Colocasia esculenta (L.) Schott in Brazil. In Breeding and Genetic Engineering: The Biology and Biotechnology Research; iConceptPressLtd.: Hong Kong, China, (2014).

19. USDA. FoodData Central. Available online: https://fdc.nal.usda.gov/ accessed on 17 February (2020). 
20. Osmud, Enachi ,Christaian, et.al., Concentrations of anti-nutritional factors in raw edible cocoyam (Colocasia esculenta) leaves, (2013).

21. Whitney EN, Rolfes SR, Understanding Nutrition, January (2011).

22. Oke \&Oke, S. Mandey, Y. H.S. Kowel, M.N.Regar and J. R. LekeFaculty, Effect of different level of energy and crude fiber from sawdust in diets on carcass quality of broiler, July 28, (2012).

23. Kaushal, P.; Kumar, V.; Sharma, H. Utilization of taro (Colocasia esculenta): A review. J. Food Sci. Technol., 52, 27-40; (2015).

24. Soudy ID, Delatour P, Grancher D (2010) Effects of traditional soaking on the nutritional profile oftaro flour (Colocasia esculenta L. Schott) produced in Chad. Revue MédVét 1:3742; (2010).

25. Food and Agriculture Organization (FAO), Roots, Tubers, Plantains and Bananas in Human Nutrition, vol. 24 of Food and Nutrition Series, Food and Agriculture Organization, Rome, Italy, (1990).

26. Kidanemariam,a,b A. C. Sukal,a A. D. Abraham,c F. Stomeo,d J. L. Dale,a A. P. James,a and R. M. Hardinga,Identification and molecular characterization of Taro bacilliform virus and Taro bacilliform C.H. virus from East Africa, Plant Pathol.; 67: 1977-1986; (2018).

27. Geering, A., Harper, G., Hart, D., Moult, S., Hull, R., \& Thomas, J. The diversity of banana streak virus strains in Uganda. Archives of Virology, 150(12), 2407-2420; (2005).

28. Kreuze, J. F., Perez, A., Untiveros, M., Quispe, D., Fuentes, S., Barker, I., \&Simon, R. Complete viral genome sequence and discovery of novel viruses by deep sequencing of small RNAs: a generic method for diagnosis, discovery and sequencing of viruses. Virology, 388(1), 1-7; (2009).

29. Ming, S. F. Y., Ping, G. W., Ping, L. W., Xing, W. X., \& Ni, H. Molecular identification and specific detection of Badnavirus from taro grown in China. Acta PhytopathologicaSinica, 43(6), 590-595; (2013).

30. Ndabikunze BK, Talwana HAL, Mongi RJ, Issa-Zacharia A, Serem AK. Proximate and mineral composition of cocoyam (Colocasia esculenta L. and Xanthosoma sagittifolium L.) grown along the Lake Victoria Basin in Tanzania and Uganda. African Journal of Food Science. 5:248-254; (2011).

31. Osawa, T.; Kato, Y. Protective role of antioxidative food factors in oxidative stress caused by hyperglycemia. Ann. N. Y. Acad. Sci., 1043, 440-451; (2005).

32. Del Rosario AV, Lorenz K. Pasta productscontaining taro (Colocasia esculenta L. Schott) and chaya (CnidoscolusChayamansa L. Mcvaugh). J Food Process Preserv.; 23:1-20 (1999).

33. Chai, R.; Ben, Q.; Sun, Y.; Qian, A.; Xu, B.; Yuan, Y. Dietary fiber intake reduces risk for colorectal adenoma: A meta-analysis. Gastroenterology, 146, 689-699 (2014).

34. Bradbury JH, Nixon RW. The acridity of raphides from the edible aroids. Journal of the Science of Food andAgriculture.;76:608-616, (1998).

35. Prajapati, R.; Kalariya, M.; Umbarkar, R.; Parmar, S.; Sheth, N. Colocasia esculenta: A potent indigenous plant. Int. J. Nutr. Pharmacol. Neurol. Dis., 1, 90; (2011).

36. Sinha S, Sandhu K, Bisht N, Naliwal T, Saini I, Kaushik P. Ascertaining the paradigm of secondary metabolism enhancement through gene level modification in therapeutic plants. Journal of Young Pharmacists. (2019).

37. Huez, Huang F, Dongke W, Ding W. 2008. Characterization of 11 new microsatellite loci in taro (Colocasia esculent). Molecular Ecology Resources (2015). 
38. Kaushik P. Standardisation of an Agroinfiltration Protocol for Eggplant Fruits and Proving its Usefulness by Over-expressing the SmHQT Gene (2019).

39. Dwivedi AK, Sen H. Correlation and path coefficient studies in taro (Colocasia esculenta var. antiquorum). J. Root Crops, 25:51-54; (1999).

40. Mengane S., Phytochemistry of some medicinal plants from Western Ghat region Journal of Pharmacy Research 1(9):1-4; January (2015).

41. Sheth AK The herbs of ayurveda. AK Sheth Publishers, AhmedabadEthnobotany and Conservation; Rao, V.R., Matthews, P.J., Eyzaguirre, P.B., Hunter, D., Eds.; Bioversity International: Rome, Italy, 2010; Volume 1(2005).

42. M.S. Kubde, S. Khadabadi, I. Farooqui, S. Deore In-vitro anthelmintic activity of Colocasia esculenta , Der Pharmacia Lettre, 2 (2), pp. 82-85; (2010).

43. Dnyaneshwar PS, Pravinkumar DP, Gurunath VM, Akashya KS. Potential use of dragon fruitand taro leaves as functional food: a review. Eur J EngSciTechnol 1(1):10-20; (2018).

44. FAO. Taro Cultivation in Asia and the Pacific, Food and Agriculture Organization of the United Nations (FAO), Rome, Italy, (1999).

45. Jirarart T, Sukruedee A, Persuade P. Chemical and physical properties of flour extracted from taro (Colocasia esculenta) grown in different regions of Thailand. Science Asia. 32:279-284; (2006).

46. Brar NS, Saini DK, Kaushik P, Chauhan J, Kamboj NK. Directing for higher seed production in vegetables. Agronomy-Climate Change \& Food Security. (2020).

47. Brar NS, Saini DK, Kaushik P, Chauhan J, Kamboj NK. Directing for Higher Seed Production in Vegetables [Internet]. Agronomy - Climate Change \& Food Security. IntechOpen; (2019). 